\title{
SENTIDOS ATRIBUÍDOS À FORMAÇÃO TÉCNICA INTEGRADA AO ENSINO MÉDIO POR ESTUDANTES
}

\author{
Jorge Washington de Amorim Juniorl \\ Lílian Caroline Urnau²
}

\section{RESUMO}

Neste trabalho, o objetivo é analisar os sentidos que estudantes atribuem à sua formação em um curso técnico integrado ao ensino médio. À luz do referencial da Psicologia Histórico-Cultural e por meio de entrevistas semiestruturadas, realizamos uma pesquisa com quatro adolescentes, estudantes do último ano do Curso de Edificações no Instituto Federal de Educação, Ciência e Tecnologia de Rondônia (IFRO). Os resultados demonstram que a contradição atravessa a formação profissional ofertada e recebida pelos estudantes, uma vez que seu objetivo é prepará-los para o mercado de trabalho e, ao mesmo tempo, auxiliar na preparação e na continuidade da escolarização no ensino superior. Tal dualidade estrutural impacta significativamente na formação de sentidos para os alunos, os quais acreditam estar em vantagem no cenário competitivo do mercado de trabalho, ao mesmo tempo em que observam desvantagens no ingresso ao ensino superior. Em vez da ênfase no ensino propedêutico, em um curso técnico, o foco maior é nos conhecimentos técnicos específicos à formação em engenharia civil e arquitetura, por exemplo. Além disso, os sentidos predominantes revelaram a contraposição entre oportunidades educativas e perspectivas de futuro para esses jovens de camadas populares. O excesso de atividades de estudo e de cobranças é por eles considerado como meio para que atinjam mais autonomia e responsabilidade, entendidas como requisitos importantes na inserção competitiva.

Palavras-chave: Adolescência. Educação Técnica integrada ao Ensino Médio. Sentidos.

\section{SENSES OF VOCATION EDUCATION INTEGRATED TO SECONDARY SCHOOL ASCRIBED BY STUDENTS}

\begin{abstract}
This paper aims at analyzing the senses that students ascribe their education in a Vocational Course Integrated to Secondary School. In the light of the Historical-

\footnotetext{
1 Mestre em Psicologia. Professor do Instituto Federal de Educação, Ciência e Tecnologia de Rondônia - IFRO Campus Porto Velho Zona Norte. Porto Velho, Rondônia, Brasil. Orcid iD: http://orcid.org/0000-0002-4961-7154. E-mail: jorge.amorim@ifro.edu.br

2 Doutora em Psicologia. Professora da Fundação Universidade Federal de Rondônia -UNIR. Porto Velho, Rondônia, Brasil. Orcid Id: http://orcid.org/0000-0001-9222-4658. E-mail: lilian.urnav@gmail.com
} 
Cultural Psychology framework and by the use of semi-structured interviews, we conducted a research with four adolescents, students of the last year of the Building Technician Course at the Federal Institute of Education, Science and Technology of Rondônia (IFRO). The results show that the contradictions pass through the vocational education offered and received by students, since it aims at preparing them to the world of work and, as well as, helping them to be prepared to access and continue schooling in higher education. It has been possible to observe that the structural duality significantly affects how students ascribe senses to their education, as they believe to be ahead in the competitive scenario of the world of work, and, at the same time, they perceive disadvantages to access Higher Education. In a Vocational course, the focus is on technical knowledge, Instead of the propaedeutic education, in the case of this research such knowledge regards to civil engineering and architecture, for instance. Furthermore, the prevalent senses on their education revealed the contrast between educational opportunities and perspectives for their future for those young people from the popular strata. They consider the excess of study activities and demands as possibilities for developing greater autonomy and responsibility, understood as important requirements in competitive insertion.

Keywords: Adolescence. Vocational Education integrated to Secondary School. Senses.

\section{LOS SENTIDOS DE FORMACIÓN TÉCNICA INTEGRADA PARA ESTUDIANTES DE LA EDUCACIÓN SECUNDARIA}

\section{RESUMEN}

En este trabajo, el objetivo es analizar los significados que los estudiantes atribuyen a su formación en un curso técnico integrado a la escuela secundaria. A la luz de referencias de la Psicología Histórico-Cultural y a través de entrevistas semiestructuradas, realizamos una Investigación con cuatro adolescentes, estudiantes del último año del Curso de Edificación en el Instituto Federal de Educación, Ciencia y Tecnología de Rondônia (IFRO). Los resultados muestran que la contradicción pasa por la formación profesional ofrecida y recibida por los estudiantes, ya que su objetivo es prepararlos para el mercado laboral y, al mismo tiempo, ayudar en la preparación y continuidad de la escolarización en la educación superior. Esta dualidad estructural afecta significativamente la formación de significados para los estudiantes, que creen que están en una ventaja en el escenario competitivo del mercado laboral, mientras observan desventajas en la entrada a la educación superior. En lugar del énfasis en la enseñanza propedéutica, en un curso técnico, el enfoque principal se centra en los conocimientos técnicos específicos de la formación en ingeniería civil y arquitectura, por ejemplo. Además, los sentidos prevalecientes revelaron el contraste entre las oportunidades educativas y las perspectivas de futuro para estos jóvenes de capas populares. El exceso de actividades de estudio y recogida es considerado por ellos como un medio para que logren una mayor autonomía y responsabilidad, entendidas como requisitos importantes en la inserción competitiva.

Palabras clave: Adolescencia. Educación profesional integrada a la escuela secundaria. Sentidos. 


\section{INTRODUÇÃO}

Na perspectiva da Psicologia Histórico-Cultural, a educação escolar desempenha um papel fundamental no desenvolvimento humano (MARTINS, 2013). No caso da educação técnica profissional integrada ao ensino médio, espera-se que os adolescentes sejam preparados não somente para 0 mundo do trabalho, mas também, em uma concepção de formação humana integral, para se desenvolver como indivíduos e profissionais que devem se relacionar com o trabalho.

Esse duplo princípio se faz presente na legislação nacional. No artigo 205 da Constituição Federal garante o desenvolvimento pleno da pessoa, ou seja, que esta seja preparada para o exercício da cidadania e para o trabalho (BRASIL, 1988). A Lei de Diretrizes e Bases da Educação n. 9394/96 (BRASIL, 1996) também prevê que essas duas dimensões sejam o objetivo formativo da educação básica. Conforme a Lei de n. 11.892/08 (BRASIL, 2008) de criação dos Institutos Federais de Educação, Ciência e Tecnologia, estes são destinados a promover uma educação integral que supere a dicotomia entre formação propedêutica e formação profissional (PACHECO, 2010), seja ofertando a educação profissional técnica integrada, concomitante ou subsequente ao ensino médio, seja ofertando cursos tecnólogos e de pós-graduação.

Mais recentemente, conforme a Lei $n^{\circ}$. 13.415/17, as escolas de ensino médio, públicas e privadas, também podem oferecer a formação profissional e técnica como um itinerário formativo, mesmo que seja uma única opção, a depender das condições institucionais.

No que se refere especificamente ao foco deste artigo, os institutos federais (IFs) constituem-se como um arranjo educacional que "[...] abre novas perspectivas para o ensino médio-técnico, por meio de uma combinação do ensino de ciências, humanidades e educação profissional e tecnológica" (SILVA et. al., 2009, p. 8-9).

O público-alvo do curso técnico integrado ao ensino médio é constituído predominantemente por adolescentes entre 15 e 19 anos. $O$ período da adolescência, conforme explica Dragunova (1973), é marcado 
por mudanças e transformações biológicas e socioculturais. Por exemplo, na sociedade capitalista, desde a modernidade, a escolha e a preparação para a futura atividade profissional compõem um evento significativo desse momento da vida.

Assim, considerando as questões que envolvem a adolescência, pretendemos esclarecer melhor suas implicações para a vida do indivíduo durante sua formação na educação profissional integrada ao ensino médio.

Durante a pesquisa, buscando essa compreensão, definimos algumas questões relevantes: quem são os estudantes ingressantes dos cursos técnicos integrados ao ensino médio; que sentidos eles atribuem à formação no Instituto Federal de Educação, Ciência e Tecnologia; se, no último ano de estudo, eles se consideram preparados para o mundo do trabalho ou para a continuidade da formação no ensino superior?

Consideramos que tais questões são relevantes não somente para o planejamento do trabalho educativo, mas também para a concretização da política de permanência e para o êxito dos institutos federais, conforme solicitação da Secretaria de Educação Profissional e Tecnológica - SETEC do Ministério da Educação a respeito do objetivo de reduzir o índice de evasão e de retenção nos IFs.

O conhecimento do perfil do adolescente que egressa o IF, bem como a compreensão de como ocorre a formação desse indivíduo podem orientar o estabelecimento de estratégias pautadas nas condições concretas dos indivíduos em formação e nas possibilidades de permanência e de êxito dessa formação, a aplicação adequada dos recursos e o redirecionamento de práticas pedagógicas que atendam às necessidades formativas autênticas dos estudantes, para além de dados meramente quantitativos que, muitas vezes, não são capazes de demonstrar a dimensão objetiva e subjetiva da permanência e do êxito do estudante, busca-se a promoção de uma formação integral, ou seja, uma formação para si e para a vida em sociedade.

Em nossa pesquisa, tivemos como objetivo compreender os sentidos que os estudantes do último ano do Curso Técnico em Edificações Integrado 
ao Ensino Médio de um campus do Instituto Federal atribuem à sua formação. Nossa intenção é fornecer subsídios aos educadores, orientar sua prática docente e promover uma melhor compreensão das relações sociais e históricas desse período de desenvolvimento humano, considerando a maneira como a sociedade se organiza no sistema capitalista e suas implicações na elaboração de políticas públicas para a educação profissional. Esperamos também que nossos educadores e docentes, munidos com os resultados dessa análise, possam intervir para que os resultados dessa política pública contribuam de forma mais efetiva no processo educativo dos jovens do país.

O artigo foi estruturado em três tópicos. No primeiro, apresentamos nosso referencial teórico sobre a educação de adolescentes para o trabalho; no segundo, o método utilizado e a análise dos dados e, no terceiro, nossas considerações finais acerca do tema.

\section{A EDUCAÇÃO DE ADOLESCENTES PARA O TRABALHO}

Partimos da ideia defendida por Martins (2013) de que a educação escolar desempenha um papel central na formação da personalidade do indivíduo nesta sociedade e o auxilia na criação de interesses, motivos e sentidos para a vida.

É pela mediação da educação escolar que a transmissão dos saberes científicos se torna possível de geração a geração, considerando-se, especialmente, o valor dos avanços e dos aprimoramentos das tecnologias para a atividade humana. A escola se configura como lócus para a apropriação do saber científico, ou seja, como um lugar no qual os conhecimentos mais ricos e elaborados podem ser socializados. Conforme elucida Duarte (2004), a escola é capaz de possibilitar a apropriação da herança de conhecimentos construídos no processo histórico e, assim, conduzir à superação da sociedade capitalista, que, segundo o autor, se apresenta como um modelo alienante e produtor de exploração.

A formação integral do indivíduo torna-se objeto da educação escolar porque desta, mais do que a preparação para a realização de atividades 
técnicas que atendam às demandas do mercado, espera-se uma formação em sentido amplo, ou seja, a promoção do desenvolvimento das funções psíquicas superiores, como pontua Martins (2013) com base em estudos de Vigotski e seguidores. Dessa perspectiva, a escola tem uma função humanizadora.

Em nossa pesquisa, compreendemos que a formação técnica profissionalizante é promotora do desenvolvimento das funções psíquicas superiores (VYGOTSKI, 1996; 2000), mas entendemos também que existem diferentes graus de alienação e humanização, ou seja, que não existe uma educação completamente emancipadora ou totalmente alienante. Dessa forma, precisamos estar atentos e vigilantes para não promover uma educação com baixo potencial de desenvolvimento do psiquismo, que se restrinja à instrumentalização e à apropriação de técnicas para as demandas mercadológicas mais relacionadas ao cotidiano. Devemos, como a própria teoria preconiza, mobilizar o psiquismo humano para que, por meio da apropriação das riquezas espirituais construídas social, cultural e historicamente e objetivadas em conhecimento, possa alçar níveis mais elevados de desenvolvimento, superando e transformando tais demandas.

A educação profissional, especialmente aquela integrada à educação básica, apresenta-se como um desafio, já que se coloca em tensão com "o projeto de educação profissional" e o "[...] projeto que busca construir a emancipação da classe trabalhadora", conforme Frigotto (2001, p. 79-80):

O desafio é, pois, o de termos a capacidade coletiva de distinguir o projeto de educação profissional patrocinado pelos organismos internacionais - Banco Mundial, Banco Interamericano de Desenvolvimento, etc. - do projeto que se busca construir, em diferentes espaços de nossa sociedade, numa perspectiva de emancipação da classe trabalhadora.

Essa compreensão conduz à reflexão sobre a educação em geral e sobre a educação profissional, bem como sobre as contraposições entre enfoques que buscam adequar indivíduos ao modelo liberal vigente e aqueles que buscam a transformação social. Araújo e Rodrigues (2010, p. 51) 
afirmam que "[...] tais abordagens consubstanciam em nossa sociedade, prioritariamente, dois projetos antitéticos de formação de trabalhadores: uma pedagogia focada no trabalho e outra pedagogia focada no capital".

Saviani (2011) nos explica que, na concepção marxista, o trabalho é uma atividade vital do ser humano que assegura sua vida e a de sua espécie, sendo gerador da dinâmica de sua transformação. Dessa perspectiva, o autor afirma que o trabalho educativo "[...] é o ato de produzir, direta e intencionalmente, em cada indivíduo singular, a humanidade que é produzida histórica e coletivamente pelo conjunto dos homens" (SAVIANI, 2011, p. 13). O trabalho educativo é capaz de produzir essa humanização nos indivíduos, instrumentalizá-los para o posicionamento social, político e ideológico e transformá-los por meio da socialização do conhecimento científico inerente aos meios de produção. Assim, contribui para a possibilidade de superação das relações de dominação da sociedade capitalista.

Para Leontiev (2004), é por meio do trabalho, como uma atividade produtiva, que os conhecimentos são transmitidos de geração a geração. Com base nisso, podemos compreender como se dá essa transmissão e como a relação do trabalho com o desenvolvimento humano é condicionada às leis sócio-históricas. $O$ autor explica que, nesse processo, o ser humano é identificado como um sujeito de trabalho, o que leva à compreensão da relação entre educação, humanização e trabalho. Na visão marxista, como atividade vital do ser humano, o trabalho é uma categoria central mediadora e geradora de conhecimentos.

Por isso, é importante problematizar a particularidade das relações entre humanização, educação e trabalho no momento em que o desenvolvimento humano é associado à preparação para o trabalho, a saber, na adolescência.

Bock (2004) explica que a Revolução Industrial, alterando a forma de vida das pessoas e sofisticando o trabalho com o advento dos avanços tecnológicos, contribuiu para a construção da concepção de adolescência na atualidade. Como consequência dessas alterações, os adolescentes 
passaram a permanecer mais tempo na escola se preparando para a nova realidade do trabalho.

Silva e Gasparin (2006, p. 2) também destacam que a Revolução Industrial, com a consequente mecanização do trabalho, causou significativas transformações em quase todas as relações humanas, sendo responsável inclusive pelas características da adolescência tal como a conhecemos na atualidade. A moratória "imposta" aos adolescentes foi a de atender aos meios produtivos que exigiam mais tempo de formação. No que tange à estrutura socioeconômica, "[...] fez-se a separação definitiva entre o capital, representado pelos donos dos meios de produção, e o trabalho, representado pelos assalariados [...]".

Leal e Mascagna (2016) destacam que a inserção do adolescente no mundo do trabalho é considerada um "marco" em sua transição para a vida adulta. A formação para o mundo do trabalho torna-se, dessa forma, fator de extrema importância. A educação escolar constitui-se, portanto, como um importante contexto para que o adolescente reflita sobre seu papel social e suas perspectivas de atuação profissional.

Vale destacar a afirmação de Bock (2004, p. 28) sobre o papel do trabalho e sobre a vida em sociedade: "[...] são duas características da vida humana que vão permitir um salto de qualidade no desenvolvimento humano." Ao conectar-se com o mundo do trabalho, o adolescente encontra as possibilidades de seu salto qualitativo em termos de desenvolvimento. Ao mesmo tempo, como vimos anteriormente, as condições do sistema vigente determinam como ocorre esse desenvolvimento: é o caso da "moratória" colocada para muitos adolescentes, conforme explica Bock (2004). Isso pode "atrasar" sua inserção no mundo do trabalho e, consequentemente, sua transição para a vida adulta, conforme justificam Leal e Mascagna (2016).

Tais reflexões são importantes para compreendermos que as características do adolescente que conhecemos em nossa sociedade são construídas historicamente. Elas não são inerentes à natureza biológica do indivíduo: estão relacionadas ao modelo econômico vigente. Isso explica, 
inclusive, a discrepância entre a faixa etária na qual classificamos o adolescente e o momento em que se espera que ele esteja inserido no mundo do trabalho, assim como os diferentes e desiguais modos da vivência dessas possibilidades entre as diferentes classes sociais, gêneros e etniasraças.

Referindo-se desenvolvimento humano, com base na Psicologia Histórico-Cultural, Anjos e Duarte (2016, p. 195-196) afirmam que a adolescência "[...] não pode ser reduzida a apenas um processo de mudanças biológicas, naturais, caracterizadas por consequentes síndromes em virtude dos "hormônios que estão a flor da pele"". Os autores a consideram "[...] como fase do desenvolvimento psicológico e fenômeno cultural" que tem "sua origem na história das transformações pelas quais passaram as sociedades, ou seja, as transformações dos modos de produção". Dessa forma, conforme apontado por Anjos e Duarte (2016), o período de desenvolvimento da adolescência não se resume aos fatores puramente biológicos, mas abrange os aspectos históricos, sociais e culturais. Assim, os interesses dos adolescentes são produto de sua atividade social, que se relaciona com o meios produtivos da sociedade em que eles estão inseridos.

\section{MÉTODO E ANÁLISE DOS DADOS}

O pressuposto da Psicologia Histórico-Cultural é o de que as atividades e relações humanas concretas, por meio da mediação semiótica (VYGOTSKI, 2000), mobilizam nossa atividade consciente, envolvendo percepção, atenção, pensamento, afetividade, memória, linguagem, imaginação, personalidade e de que tais processos são, ao mesmo tempo, sociais e individuais, universais e singulares.

Em nossa pesquisa, procuramos apreender os sentidos da formação no ensino técnico para adolescentes e partimos da compreensão de que:

[...] O sentido de uma palavra é a soma de todos os fatos psicológicos que ela desperta em nossa consciência. Assim, o sentido é sempre uma formação dinâmica, fluída, complexa, que tem várias 
zonas de estabilidade variada. O significado é apenas uma dessas zonas do sentido que a palavra adquire no contexto de algum discurso e, ademais, uma zona mais estável, uniforme e exata. Como se sabe, em contextos diferentes a palavra muda facilmente de sentido. O significado, ao contrário, é um ponto imóvel e imutável que permanece estável em todas as mudanças de sentido da palavra em diferentes contextos. Foi essa mudança de sentido que conseguimos estabelecer como fato fundamental na análise semântica da linguagem. O sentido real de uma palavra é inconstante. Em uma operação ela aparece com um sentido, em outra, adquire outro. Esse dinamismo do sentido é o que nos leva ao problema de Paulham, ao problema da correlação entre significado e sentido. Tomada isoladamente no léxico, a palavra tem apenas um significado. Mas este não é mais que uma potência que se realiza no discurso vivo, no qual o significado é apenas uma pedra no edifício do sentido (VIGOTSKI, 2000, p. 465).

Realizamos entrevistas semiestruturadas, gravando-as em microgravador digital. Orientamo-nos por um roteiro de questões sobre a formação no IFRO, as semelhanças e as diferenças entre eles e outras escolas, as expectativas antes e após o ingresso, a relação da formação com a vida pessoal, social, profissional, etc.

Concebemos esse roteiro como um norte, um ponto de partida para o desenvolvimento da entrevista, procurando construir a relação entrevistadoentrevistador de maneira mais aberta. Como os participantes não produzem informações de maneira linear, por diversas vezes empregamos uma forma mais flexível que nos permitisse fazer pequenas intervenções. Pautamo-nos em Szymanski $(2018$, p. 17), para quem a intervenção é "[...] o resultado de um processo de tomada de consciência desencadeado pela atuação do entrevistador, no sentido de explicitar sua compreensão do discurso do entrevistado, de tornar presente e dar voz às ideias que foram expressas por ele". Em nossas intervenções, procuramos não enviesar a pesquisa, mas ampliar as informações fornecidas pelo entrevistado sobre os sentidos atribuídos por ele à sua formação.

Participaram desta pesquisa quatro adolescentes com idades entre 18 e 20 anos, todos cursantes do último ano do Curso Técnico em Edificações Integrado ao Ensino Médio, com duração de quatro anos, de um campus do Instituto Federal de Educação, Ciência e Tecnologia de Rondônia. Para resguardar o sigilo dos participantes da pesquisa, identificamos os alunos 
com nomes fictícios como: Ana, Antônio, Leonardo e Valéria. No Quadro 1, apresentamos algumas informações relevantes:

QUADRO 1 - Sujeitos de pesquisa

\begin{tabular}{|r|c|c|c|c|}
\hline Informações/Questões & Antônio & Valéria & Leonardo & Ana \\
\hline $\begin{array}{r}\text { Sexo/Idade } \\
\text { ano escolar? }\end{array}$ & $\mathrm{M} / 18$ & $\mathrm{~F} / 20$ & $\mathrm{M} / 19$ & $\mathrm{~F} / 18$ \\
\hline Escolaridade dos pais & $\begin{array}{c}\text { Ensino Fund. } \\
\text { incompleto } \\
\text { (pai e mãe) }\end{array}$ & $\begin{array}{c}\text { Nível Médio } \\
\text { completo } \\
\text { (pai e mãe) }\end{array}$ & $\begin{array}{c}\text { Ensino } \\
\text { superior } \\
\text { completo } \\
\text { (pai e mãe) }\end{array}$ & $\begin{array}{c}\text { Ensino } \\
\text { superior } \\
\text { completo } \\
\text { (pai e mãe) }\end{array}$ \\
\hline $\begin{array}{r}\text { Identidade Étnico- } \\
\text { Racial }\end{array}$ & Negro & Pardo & Pardo & Branco \\
\hline Estado civil do aluno & Solteiro & Solteiro & Solteiro & Solteira \\
\hline
\end{tabular}

Fonte: elaborado pelo próprio autor com base no questionário socioeconômico, 2019.

Adotamos os procedimentos éticos recomendados nas resoluções $n$. $^{\circ}$ 466/2012 e n 510/2016 do Conselho Nacional de Saúde, que tratam de orientações legais para o desenvolvimento de pesquisas com seres humanos. A proposta de pesquisa foi submetida ao Comitê de Ética em Pesquisa - CEP, da UNIR e o parecer positivo foi aprovado sob o número 2.450.710.

Ao definir as categorias de análise das entrevistas, procuramos atentar para as semelhanças, as contradições e as complementaridades apresentadas nas falas de um mesmo participante, inclusive comparando-as com as dos demais. Após várias leituras, definimos as seguintes categorias:

a) Base comum x base profissionalizante: integração ou cisão entre o ensino profissionalizante e o ensino médio no dia a dia do estudante;

b) Sentido da formação: educação humanizadora x educação alienante;

c) Instrumentalização para o trabalho: perspectivas de futuro.

a) Base comum $x$ base profissionalizante: integração ou cisão entre o ensino profissionalizante e o ensino médio no dia a dia do estudante 
Utilizamos esta categoria de análise para abordar e discutir as falas dos alunos, procurando traduzir para o leitor os sentidos por eles atribuídos à organização curricular, às unidades curriculares e à práxis pedagógica. 0 objetivo é compreender como o IFRO concebe e dissemina a questão da integração entre ensino médio e técnico.

[...] tem aquela diferença de [escola] particular pra federal. E também no IFRO, por ser algo tão grande e por ter matérias técnicas também, matérias que eu nunca tinha visto na vida [...]. Valéria

[...] minha prima não estuda aqui, e ela não tem curso técnico. A base dela com relação ao ensino médio é muito mais pesada, é muito mais ampla do que a minha. Só vim ter história aqui no $3^{\circ}$ e no $4^{\circ}$ ano, sendo que exigem muito de história no ENEM. Se eu tivesse tido humanas desde o início eu acho que agora eu estaria muito mais preparada pro ENEM pra fazer a parte de humanas [...]. Valéria

[...] Porque, se, eu, em um dia, tenho prova de matéria técnica, tenho prova de ensino básico, eu vou ficar assim "Meu Deus, qual que eu dou mais peso? Ensino básico, ou ensino técnico?". Valéria

[...] todo final de bimestre! É uma loucura, a gente fica doidinho, doidinho, doidinho estudando. Nossa! Eu passo uma semana, duas semanas, sem parar, só estudando, estudando, estudando, fazendo atividade, estudando. Ana

[...] Bem pesado. E às vezes é tipo, alguns professores passavam cinco métodos avaliativos diferentes, passavam cinco trabalhos, uma prova, seis trabalhos uma prova, era loucura. Ana

[...]Aqui não é só o comum que a gente tem em outras escolas, fora. A gente tem o comum que tem em outras escolas e tem mais ensino técnico [...]. Leonardo

Considerando as falas dos alunos Ana, Valéria e Leonardo, podemos inferir que eles sentem a necessidade de encontrar uma maneira mais eficiente de administrar sua própria agenda de estudo para atender às demandas encontradas ao longo da formação, as quais lhes parecem excessivas. 
Soa-nos que a grade e a organização das duas formações não são efetivamente integradas, o que é indicado também em outras situações das entrevistas ou em documentos, como o Projeto Político Pedagógico do curso. Além do predomínio da cisão entre as disciplinas da base comum e as da base profissionalizante, também não há integração entre unidades curriculares da mesma base, o que ainda se apresenta como um desafio para a instituição. As disciplinas, os projetos $e$ as atividades são independentes uns dos outros, gerando nos estudantes a impressão de sobrecarga e "peso".

Tal cisão se reflete também nos dois caminhos diferenciados que se apresentam como possíveis após a conclusão do curso. Referem-se os entrevistados ao ENEM/ingresso no ensino superior ou à inserção no mercado de trabalho. Historicamente, em nosso país, as modalidades de ensino técnico visam a formação das classes operárias/pobres para uma inserção mais rápida no mercado de trabalho, as atividades manuais com menor remuneração e prestígio social, considerando-se a divisão clássica entre o trabalho manual e o intelectual que impera na sociedade capitalista, com algumas inovações neoliberais (MOURA, 2007). Ocorre que, no imaginário dessa sociedade, altamente elitista, o ensino superior ainda é extremamente valorizado, o que significa que a formação fornecida pelos Institutos Federais é usada como trampolim para o ensino superior.

No entanto, não podemos deixar de mencionar que esse modelo, conforme explicitam os quatro entrevistados, tem-se constituído como um importante espaço gerador de oportunidades a jovens pobres, negros, até então não existentes em nosso país. É o que evidenciam as falas de Leonardo:

Eu estava certo que eu ia sair [do IFRO], então, eu meio que deixei de lado as coisas técnicas. Só que, como eu tinha uma professora muito boa, que envolvia muito a gente em projeto [...]. Então eu peguei e comecei a me envolver em projeto e me envolver mais nas matérias técnicas e tirei pra minha conclusão que seria realmente melhor pra mim mesmo que eu perdesse um ano [pelo fato do ensino técnico exigir um ano a mais de formação]. Leonardo 
Sim, eu indicaria porque o IFRO é uma instituição excelente e, devido as oportunidades, a gente pode fazer muita coisa aqui dentro. E tem o técnico também que tu vai fazer o ensino médio lá e vai sair com o técnico já é um ponto positivo. Leonardo

Entre as oportunidades mencionadas por Leonardo e os outros adolescentes estão: cursos de línguas estrangeiras; exercícios de exposição pública (falar em público) que os auxiliam em outros domínios da vida; elaboração de projetos; atividades científicas e de pesquisa; possibilidade de acessar o ensino superior, oportunidades de realizar intercâmbios culturais em outros países etc. Tais aspectos demonstram as contradições que ainda prevalecem nesse novo modelo nacional de educação técnica integrada ao ensino médio porque a sociedade apresenta as mesmas contradições. Ao mesmo tempo, revelam sua importância para a vida dos adolescentes que podem acessar esses cursos.

\section{b) O sentido da formação: humanização $x$ alienação}

A escola é, nesta sociedade, um espaço fundamental de formação humana, não apenas porque se responsabiliza pela transmissão e pela apropriação dos conteúdos científicos, mas também porque nela aprendemos a nos relacionar com os outros, incorporamos valores sociais e nos desenvolvemos como humanos. No caso de adolescentes, cujas expectativas sociais são de preparação para a vida adulta, relacionada à independência da família, isso significa caminhar mais alguns passos no processo de singularização (MARTINS, 2013; DUARTE, 2013).

Essa questão se fez presente ao longo das entrevistas com os quatro participantes, mesmo que as perguntas não estivessem diretamente direcionadas a ela, o que evidencia a necessidade de uma reflexão.

Para avançar na discussão, apresentaremos alguns trechos de respostas referentes a uma mesma pergunta: "Como você descreve sua formação no IFRO?". 
[...] amadureci muito no IFRO, e responsabilidades também, que foi acho que parte do que me ajudou a amadurecer. Eles competem muita responsabilidade com os alunos. O IFRO eu gosto que ele faça isso, porque ele dá muita autonomia e responsabilidade para o aluno, isso faz com que (a gente) aprenda a crescer e ter responsabilidade [...]. Ana

[...] eu acho que como pessoa também eu entrei no IFRO e evoluí bastante, amadureci bastante, eu fui obrigada assim a amadurecer mais rápido, porque aqui é como se fosse uma faculdade, te propõem as mesmas oportunidades que uma faculdade, mas também tem o mesmo peso que uma [faculdade] e a mesma carga.

[...] tudo era bonitinho, pegavam na tua mão, faziam tudo, e aqui eu vejo que é muito mais complicado, tem que ter paciência. Eu tenho que saber o que eu vou fazer, o que eu posso, o que eu não posso fazer. Acho que é isso. Valéria

[...] O If ele me deu um crescimento muito, muito, muito grande em relação ao conhecimento acadêmico e eu ainda tomei muita maturidade. Então ele não só me ajudou, na formação técnica, na formação de trabalhos, a forma de você se dar no mercado de trabalho, como se comportar em apresentações, coisas acadêmicas na vida de um estudante.

[...] Então me deu a maturidade em ter amigos e saber quem é o meu amigo. Me deu maturidade também, como eu sou cristão, então a leitura me incentivou a ler aquilo que eu creio. Então abrangeu a minha mente teológica, e hoje eu ministro, eu dou aula para jovem, hoje eu dou aula em escola dominical, hoje eu apresento trabalhos e pessoas pedem conselho. Então me deu uma maturidade de vida, me deu uma maturidade acadêmica muito boa. Antônio

Acredito que o IFRO ele... ele não possa, mas faz a gente evoluir, crescer bastante na mentalidade, coisa que a gente não cresceria tanto se a gente estudasse em outra escola. Por exemplo, devido à quantidade de carga que é colocada sobre a gente, de responsabilidades, entendeu?! Então acredito que é muito importante pro meu crescimento. Me ajudou muito em diversos fatores, diversas áreas da minha vida. Eu acho que se eu, se eu estudasse em outro lugar, eu provavelmente não seria a mesma pessoa, seria menos maduro.

[...] Eu acho que, devido às responsabilidades que a gente tem aqui, que não é só o comum que tem em outras escolas, a gente tem mais o ensino técnico. Leonardo

A repetição das palavras amadurecer/amadurecimento, crescimento e responsabilidade evidencia a centralidade do sentido do desenvolvimento 
humano na formação escolar e, nesse caso específico da formação promovida pelo IFRO, remete-nos à ideia vigotskiana de que "[...] a periodização do desenvolvimento opera numa espiral dialética, envolvendo avanços e recuos, saltos e paralisações. Nesse processo, são produzidas as neoformações e gestadas as atividades-guia de cada período" (TULESKI; EIDT, 2016, p. 57). Percebemos que a concepção de desenvolvimento apresentada pelos adolescentes, a noção de responsabilidade que os orienta neste modelo social, a perspectiva construída em suas formações são centradas em atividades e conhecimentos que os adaptem às demandas mercadológicas vigentes e, em alguns casos, parecem pretender "acelerar" o desenvolvimento do adolescente para atender às necessidades mercadológicas.

Nesse sentido, ao comparar o ensino médio a uma faculdade, que seria voltada para jovens de faixa-etária posterior à sua, Valéria revela que a educação ofertada pelo IFRO "antecipa" o formato de desenvolvimento de autonomia e de responsabilidade do aluno, de flexibilidade do currículo etc., mais comum ao ensino superior.

Por um lado, isso promove o "amadurecimento", a expansão das aprendizagens para outros espaços, como fica evidente na fala de Antônio. Este adolescente considera que a habilidade de se apresentar em público, de liderar outros jovens em sua comunidade religiosa, é uma apropriação resultante da educação recebida no IFRO.

Por outro lado, essa educação pode promover o sofrimento, como ficou evidenciado nas falas dos entrevistados que se referiram ao "peso" e à "sobrecarga" de atividades de estudo e à ausência de tempo livre. Isso fica claro nas falas de Ana e Valéria:

[...] acho que se eu me organizasse melhor o meu tempo ia estar mais bem dividido eu não ia sofrer tanto. Ana

[...] quando eu entrei aqui foi uma coisa, foi um peso muito grande, porque no meu $1^{\circ}$ ano foi o primeiro ano que eu fiquei de recuperação, o primeiro ano que eu fiquei de final, foi o primeiro ano que eu tirei nota baixa, que eu zerei prova, que aconteceu tudo! [...] foi a primeira vez que eu reprovei foi aqui também. Valéria 
Assim, cabe questionar se as demandas da educação ofertada pelo IFRO não significam, contraditoriamente, acelerar $\circ$ processo de desenvolvimento do adolescente em razão de demandas do mercado, as quais exigem prontidão, adaptabilidade e conformação às pressões econômicas e sociais.

Podemos, neste caso, nos apoiar na análise de Foucault (1987), que, em Vigiar e Punir, mostra como o modelo escolar vigente funciona para a docilização dos corpos para a produção capitalista. Segundo o autor, por meio do desenvolvimento do autocontrole e da autodisciplina, promove-se a ampliação da capacidade produtiva. Da perspectiva marxista, tal modelo contribui para a alienação, o que fica evidente nas falas dos estudantes apresentadas a seguir.

No profissional, como eu disse, ele [o IFRO] trabalha muito a questão da responsabilidade, com responsabilidade e empenho, tu consegues chegar muito longe. E eu acho que é uma coisa que o mercado de trabalho olha muito, que a pessoa seja responsável, empenhada e esforçada. E acho que é uma coisa que IFRO trabalha muito, o esforço pessoal de cada um.

[...] muito bom pra questão, pra questão trabalhista, o trabalho em grupo é uma coisa que o mercado de trabalho preza muito. Ana

[...] entrar no IFRO é uma oportunidade grande, poucos conseguem e eu com essa oportunidade não podia desperdiçar. Segundo, apesar de ser forte o ensino aqui, ser pesado, com o tanto de cobrança que a gente tem, eu sei que é para o meu bem, e que futuramente isso vai trazer grandes resultados pra mim. Eu vou ser mais responsável, saber mais da minha área, estar mais inteirada dentro da minha área, eu vou ter mais prestígio no mercado de trabalho [...]. [...] então ele [o IFRO] abre muitas portas pra gente e até pro mercado de trabalho, muitas vagas de estágio, de emprego, você consegue por aqui. Ana

[...] me fez capaz de atuar naquilo que eu tenho de formação. É aquilo que eu sou formado, eu estou... pronto para aquilo. É como se fosse meio que um grupo de soldados! Pra essa guerra ev estou pronto. Antônio

Então eu acho que se o instituto não tivesse, é, aparecido na minha vida, se não tivesse entrado no instituto, acho que eu seria uma... profissional ainda bem inexperiente e estaria 
aprendendo ainda o que é mercado de trabalho, o que provavelmente teria muita dificuldade ainda quando entrasse no mercado de trabalho. Valéria

[...] Então se eu sair do estágio, sair do If e eu entrar numa empresa assim pra poder trabalhar na minha área, eu acho que eu não vou ter tanta dificuldade com o que eu estou [aprendendo] no curso. Valéria

[...] Mas eu acredito que também contou o ponto da realização pessoal, que eu ia sentir um certo orgulho depois que terminasse tudo isso eu ia olhar pra trás e ia ver que valeu tudo a pena pela vantagem competitiva no mercado de trabalho, no currículo, e pela, satisfação pessoal também. Leonardo

É possível reconhecer as crises causadas pela tensão entre as demandas externas sociais (entenda-se aqui, acadêmicas e mercado de trabalho) e as rupturas do período anterior, quando a atividade guia se constituía tão somente como atividade de estudo. Essas crises começam a dar lugar, na adolescência, ao relacionamento com os pares e à preocupação com a preparação para o mundo adulto (VYGOSTKI, 1996; ELKONIN, 1987).

Em sua fala, Valéria afirma que o processo de se tornar adulto é "pesado", o que nos remete à crise da idade, apontada por Vigotski (1996) e Elkonin (1987).

[...] todo jovem tem aquele negócio de ter que estudar, ter que trabalhar, é muito pesado o fato dele saber que está virando adulto e ele tem que terminar de estudar, para poder trabalhar, poder ter dinheiro para se sustentar. Valéria

Ao perceber a necessidade de se preparar para o mundo do trabalho e de assumir a responsabilidade por sua própria vida, o aluno passa por crises que inicialmente o desestabilizam. Depois, no percurso, desafiado pela nova orientação (atividade guia), na periodização do desenvolvimento de seu psiquismo, ele as supera e reencontra o equilíbrio.

A ênfase do IFRO, e possivelmente de outros IFs, na formação para o mercado de trabalho revela que o sentido atribuído à luta pela sobrevivência, à orientação para lidar com a esfera do imediato do 
educando, à formação é o de instrumentalizar o aluno para atender demandas mercadológicas e perpetuar a sociedade de classes, na qual a classe dominada é provida de uma educação unilateral.

Em nosso referencial teórico, apoiamo-nos em Jesus (2005, p. 118) que, ao refletir sobre a construção da sociedade socialista, fundamenta-se em Gramsci: "A pedagogia socialista não se pode limitar a uma preparação genérica para a vida, nem apenas à capacitação profissional, mas deve abraçar todo o homem, penetrar no íntimo de sua personalidade, formandoo omnilateralmente". Tal formação deve desenvolver os aspectos físico, moral e político, bem como instrumentalizar o educando para sua inserção nos meios produtivos.

Esse referencial é utilizado nesta análise porque entendemos que, conforme defende Duarte (2013), a educação escolar deve superar o que está dado na vida cotidiana. Por meio de uma educação intencional e sistematizada, o aluno consegue ir além do que está posto em seu imediato, podendo, assim, pensar em sua reprodução como indivíduo e na reprodução da sociedade de forma crítica, encontrar soluções para os problemas e possíveis degenerações causados pelo modelo vigente, já dado no momento em que adentra a sociedade.

\section{c) Instrumentalização para o trabalho: perspectivas de futuro}

Durante a entrevista, buscamos investigar as expectativas que os estudantes tinham antes de ingressar no curso técnico integrado ao ensino médio e as expectativas de futuro obtidas após a formação. Vejamos as falas dos adolescentes entrevistados.

[...] eu pensei: "Não, vou entrar e vou me apaixonar por engenharia" e não tá sendo muito isso (risos). E também (tinha a expectativa) que ia abrir mais portas para o mercado de trabalho, mas não foi bem assim. Ana

Ainda espero conseguir trabalhar nessa área, como eu disse, eu estou tendo algumas oportunidades que eu vejo que muitas pessoas não tiveram. Que eu consiga seguir na área que estou, como técnica ou aprendiz, tanto faz, ou estagiária 
até, e também entrar na faculdade de engenharia civil. Eu acho que é o que eu quero seguir. Ana

Meu sonho foi sempre conhecer a área da engenharia. Na verdade, na terceira série a professora perguntou o que nós queríamos ser, eu falei que eu queria ser pedreiro. Eu falei: "Eu preciso entrar no IFRO pra saber o que que é engenharia!" Mas eu ainda tenho um sonho, e creio que isso, a faculdade, seja aqui ou em outra faculdade, eu possa chegar a um intercâmbio. Antônio

[...] então quando você ingressa nessa escola, ela te dá um leque muito grande e te abre várias oportunidades. Por exemplo, se eu te contar, eu sempre gostei da engenharia, e se eu te falar que eu também amo história agora? E se eu te falar que eu também amo filosofia? E a igreja, que tem a teologia, e teologia, filosofia e história se batem certinho. Então é aquilo o meu hobby, que eu gosto, e o meu sonho que é fazer engenharia, meu sonho, hobby e a minha vida profissional, que eu não vejo outra coisa a não ser engenharia.

\section{Antônio}

[...] quero falar alemão, inglês, eu quero fazer história, teologia na Alemanha, e eu estou correndo atrás disso. Antônio

[...] eu não sabia, eu não sabia nem que carreira eu ia seguir com 14 anos. Mas eu entrei aqui, eu gostei do curso e acabei tendo que, resolvendo, continuar. Na época eu achava que um técnico em edificações ia ser só aquilo ali, que eu não ia poder fazer engenharia civil, arquitetura, ou qualquer outro tipo de engenharia que tem na vida. Valeria

[...] eu acho que é algo bem complicado, porque o mercado de trabalho hoje está bem exigente. Não sei se eu vou conseguir um emprego quando eu sair daqui. Quando eu sair daqui eu vou ter que arranjar um emprego não sei de que, não sei se vai ser na área, mas eu vou ter que arranjar um emprego. Valeria

[...] está dificultando um pouco o dinheiro. Eu quero fazer uma federal, não quero fazer uma particular. Se eu não conseguir fazer numa federal, acho que vou ter que fazer concurso. Valeria

[...] como eu queria engenharia na época, aí eu me inscrevi em Edificações. Então o que eu pensava era entrar no IFRO, já ir melhorando o meu currículo, porque eu ia ter um [curso] técnico, dar continuidade na engenharia, ter numa carreira boa. Leonardo

[...] não vou seguir a área de engenharia. Eu entrei também pra ter uma base. Eu vi que não era o que eu queria. Eu pretendo me formar aqui e ingressar em alguma federal. Eu estou meio em dúvida, mas o que eu estou pensando mesmo é Psicologia. Leonardo 
Podemos observar que, no que se refere ao anseio pela inserção no mundo do trabalho, as expectativas que os alunos tinham antes de ingressar no processo formativo do IFRO permaneceram inalteradas depois de terem passado por esse processo.

Entretanto, há evidências de muitas transformações na proporção desses anseios. Por exemplo, conforme a afirmação de Antônio, antes de ingressar no IFRO, seu sonho de vida era ser pedreiro. Depois que ingressou, passou a amar História e Filosofia e queria aprender inglês e alemão para fazer intercâmbio e tornar-se engenheiro. Analisando seu perfil, notaremos que se trata de um adolescente que se autodeclara negro, oriundo de escola pública e de pais que possuem pouca escolaridade. Observamos, portanto, que novas realidades e possibilidades se abrem com o processo de escolarização.

Conforme as entrevistas, antes de iniciar o processo formativo, as expectativas desses participantes estavam voltadas para maiores e melhores oportunidades de instrumentalização para o mercado, bem como para o ingresso no nível superior.

Pelo fato de o Instituto Federal ofertar o curso técnico integrado ao ensino médio, os alunos do Curso de Edificações expressaram o desejo de iniciar a formação no curso técnico, para, no nível superior, conseguir entrar, em Engenharia, pois, estando familiarizados com o campo de atuação, estariam um passo à frente de quem não tivesse a mesma formação técnica.

Quatro anos mais velhos, na iminência de concluir o processo formativo e estando mais próximos da fase adulta, com demandas externas e internas diferentes das que tinham quando iniciaram a trajetória formativa, os estudantes se referem às suas experiências e expectativas e reafirmam algumas das que tinham antes de iniciar o processo formativo. Indicam, assim, que esse processo reforçou as expectativas a respeito da instrumentalização para o trabalho.

A forma como eles se referem ao período em que estão na iminência de entrar revela que eles parecem vê-lo com um pouco mais de realidade.

Revista Exitus, Santarém/PA, Vol. 10, p. 01-29, e020033, 2020. 
Alguns declaram que já conhecem e experimentam algumas das dificuldades em seus cotidianos, que percebem a competição enfrentada para ocupar um lugar nas universidades públicas e para garantir uma posição no mercado de trabalho.

Ainda no contexto da instrumentalização para o trabalho e das perspectivas de futuro, buscamos compreender, nas expressões dos participantes de pesquisa, o sentido que a educação escolar tem para os educandos. Atribuímos suas expectativas ao cenário de recessão econômica ao desemprego estrutural, à competição, à fome, à violência e a todas as repercussões negativas da incapacidade do modo de produção vigente para equalizar e oferecer soluções. É esse cenário que explica por que a preparação/instrumentalização para se tornar competitivo e qualificado a uma vaga na universidade e no mercado de trabalho se apresenta com tanta proeminência entre as preocupações e prioridades dos educandos a respeito de seu futuro e da educação.

Entendemos que o sentido que os estudantes atribuem à sua formação se constitui na relação com os significados sociais e com os sentidos atribuídos por outras pessoas ao seu redor, como os professores, a família, os amigos etc. A esse respeito, vale retomar a fala do Antônio: "Eu tive uma professora que entrou e falou bem assim "Gente, mercado de trabalho está aí. Quanto de estágio vocês conseguirem, façam!". Isso reforça a ideia de que o sentido que o aluno elabora sobre sua formação é influenciado pelos significados sociais e pelo sentido que seus formadores transmitem na prática educativa.

$\mathrm{Na}$ ânsia por expandir nossa compreensão a respeito da maneira como o aluno se percebe em relação à sua própria formação, bem como para abstrair o sentido e a finalidade da formação na vida de cada um dos educandos, lançamos uma pergunta sobre a formação no IFRO, levando o estudante a emitir seu ponto de vista e a descrever essa formação. Conseguimos, assim, observar como esses adolescentes objetivam em si tal formação. 
Já informamos que, em nossa pesquisa, adotamos como parâmetro de análise a proposta de formação integral do indivíduo contida no pensamento de Gramsci, inspirado por Karl Marx e apresentado por Jesus (2005) e Dore (2014). Apoiando-nos em seus estudiosos e comentadores mais contemporâneos, pudemos traçar alguns paralelos e compreender, nas respostas dadas pelos participantes, que a preocupação com o desenvolvimento do senso político, da arte, da filosofia e de tudo o que pode promover no educando a complexificação da consciência não está contemplada em tal formação.

É relevante pontuar que ensino integrado e educação integral, apesar de terem uma estrutura léxica muito similar, diferenciam-se enormemente quanto às suas acepções. O ensino integrado nos IFs busca integrar o ensino propedêutico à formação técnica profissionalizante. Já, a educação integral deriva da escola unitária de Gramsci e da educação politécnica pensada por Marx. Por isso, vale abordar o entendimento de Marx sobre o conceito de educação integral politécnica. Conforme afirmam Moura, Lima Filho e Silva (2015, p. 1060), "Ao tratar de educação intelectual, física e tecnológica, Marx está claramente sinalizando para a formação integral do ser humano, ou seja, uma formação onilateral".

A respeito do movimento de apropriação e de objetivação ocorrido ao longo de suas vidas e não somente na trajetória de formação do curso técnico integrado ao ensino médio, os alunos enfatizam que puderam apreender e objetivar em si uma formação promotora de responsabilidade e amadurecimento. Tais características são associadas por eles às competências desenvolvidas no curso no sentido de capacitá-los para lidar com suas vidas cotidianas e pragmáticas, qualificá-los para o estudo no nível superior e instrumentalizá-los para o mercado de trabalho.

Considerando nossa perspectiva de análise, cabe ressalvar que instrumentalizar o educando para lidar com as demandas práticas e imediatas não caracteriza em si um problema, pois essa é uma tarefa das escolas de formação técnica. No entanto, torna-se um problema quando a formação se restringe a essas demandas. Na concepção de formação 
omnilateral, integral, aqui apresentada como parâmetro, a formação deve, sim, integrar o indivíduo aos meios produtivos, permitir que ele viva sua individualidade em si, habilitá-lo a viver o ser genérico que é, mas não se encerrar nisso (DUARTE, 2013; HELLER, 2004).

Portanto, podemos concluir que a alienação na educação escolar consiste justamente em limitar o aluno a obter conhecimentos ou competências que atendam a demandas utilitaristas e restritas ao seu imediato. Já, a educação humanizadora, tem como cerne garantir que o educando se emancipe, transite e faça escolhas mais livres e conscientes, já que ele estaria ciente de sua singularidade e genericidade, saberia lidar com os aspectos mais pragmáticos de sua reprodução individual e social e, por fim, viveria sua individualidade em si e para si conscientemente e volitivamente.

\section{CONSIDERAÇÕES FINAIS}

Analisando as entrevistas realizadas com os adolescentes estudantes conforme nossas compreensões teóricas, observamos que, em alguns aspectos, o sentido que cada um atribui à sua formação difere, assemelhase ou complementa o de outros. Pudemos também verificar o significado social atribuído à formação profissional, as expectativas sociais em relação ao adolescente e à sua inserção no mercado de trabalho, as demandas das famílias, a partir de suas diferenças socioeconômicas.

As entrevistas também revelaram, dentre outros dados, que a relação com os pares, ou seja, a comunicação íntima pessoal, é uma importante geradora de motivos para os estudos. Conforme destaca Elkonin (1987), a comunicação íntima pessoal na atividade de estudo, que já é orientada para a formação profissional rumo à construção da autonomia do jovem, é uma atividade guia nesse período intermediário entre a infância e a fase adulta.

Em nossa pesquisa, observamos que o público ingressante no curso técnico integrado ao ensino médio é constituído de adolescentes 
provenientes de diferentes condições socioeconômicas, centralmente de classes populares e média.

Conforme as entrevistas, os adolescentes se percebem mais preparados para o mundo do trabalho do que seus pares provenientes de outras instituições de ensino que ofertam apenas a educação básica regular, ou seja, não-profissionalizante. Ao mesmo tempo, dizem-se mais divididos entre o currículo profissionalizante e o currículo da educação básica, chegando a se considerar em desvantagem na concorrência para o Exame Nacional de Ensino Médio - ENEM.

Consideram também que, se ingressassem em um curso de nível superior, estariam mais familiarizados e preparados para atender às expectativas que os estudos acadêmicos e o mercado demandam dos jovens. Isso porque, em seu entendimento, o curso técnico integrado ao ensino médio exigiu que tivessem mais responsabilidade e capacidade de auto-gestão, orientando-os por demandas e paradigmas que não radicam apenas na expectativa de adentrar o nível superior.

Observar o sofrimento e o desconforto do estudante e, ao mesmo tempo, o entusiasmo com o acesso a oportunidades educacionais importantes foi uma forma de mostrar a relevância de se reconhecer a atividade guia do adolescente e buscar intervir positivamente nas mediações pedagógicas. No trabalho educativo, é mister que o educador seja sensível a um processo humano e humanizador, que compreenda e seja compassivo com os sentimentos do educando. Assim, em um processo que envolve afeto e cognição, poderá balizar e orientar os jovens, tranquilizandoos quanto aos sentimentos que surgem nesse período, concebido pela teoria como uma transição.

Em nosso país, dependendo da classe social à qual o adolescente pertence, este terá oportunidades educativas distintas, mas a alienação estará presente, já que o sistema capitalista a produz. A educação escolar tem um papel fundamental na formação do indivíduo, sendo elemento potencial na superação de sua condição social (DUARTE, 2013). Sua função é promover o desenvolvimento das funções psíquicas superiores (MARTINS, 
2013), fornecer conteúdos que levem os alunos a compreender, idealmente, as condições materiais de seu entorno e produzir, no plano material, as condições e formas de superação. No processo dialético e contínuo de apropriação e objetivação, os educandos tomam consciência das relações materialmente constituídas para ter, então, alguma possibilidade de elaborar intervenções que favoreçam a superação das degenerações que o sistema vigente apresenta e poder fazer escolhas conscientes, agir de forma mais consciente, livremente, de acordo com sua vontade e, obviamente, no limite de suas condições concretas.

É mister não imputar, injustamente, à formação ofertada pelo IFRO toda a responsabilidade pelos sentidos expressos nos discursos dos alunos, pois a estrutura de nossa sociedade neoliberal apresenta uma dualidade estrutural, um conflito de interesses. Dessa maneira, em nosso trabalho, orientados pelas teorias apresentadas, posicionamo-nos no sentido de compreender os desafios a serem enfrentados por uma nação para superar a ideologia que a engendrou.

Posicionamo-nos também a favor do ideal apresentado por Pacheco (2010, p. 14): "[...] derrubar barreiras entre o ensino técnico e o científico, articulando trabalho, ciência e a cultura na perspectiva da emancipação humana [...]". Orientados pelo pensamento marxiano, gramsciano e vigotskiano, compreendemos que a complexificação do psiquismo e a emancipação, por meio da socialização dos conhecimentos mais ricos e elaborados pela humanidade, apresentam-se como uma tarefa que vai além das paredes da escola. Não estamos afirmando, com isso, que a educação esteja isenta de auxiliar a sociedade na busca de soluções para as degenerações geradas por uma ideologia neoliberal que nos expõe à competição, à exploração, à fome, à violência e ao uso negligente de nossos recursos naturais, com suas sequelas.

\section{REFERÊNCIAS}

ANJOS, R. E. dos; DUARTE, N. A adolescência inicial: comunicação íntima pessoal, atividade de estudo e formação de conceitos. In: MARTINS, L. M. et 
al. (org.). Periodização Histórico-Cultural do desenvolvimento psíquico: do nascimento à velhice. Campinas, SP: Autores Associados, 2016, p. 195-219.

BOCK, A. M. B. A perspectiva sócio-histórica de Leontiev e a crítica à naturalização à formação do ser humano: a adolescência em questão. Cad. Cedes, Campinas, v. 24, n. 62, p. 24-43, abril 2004. Disponível em: http://www.cedes.unicamp.br. Acesso em: 15 mar. 2018.

BRASIL. [Constituição (1988)]. Constituição da República Federativa do Brasil. Disponível em:

http://www.planalto.gov.br/ccivil_03/Constituicao/Constituicao.htm. Acesso em: 10 jul. 2018.

BRASIL. Lei de Diretrizes e Bases da Educação Nacional - LDBEN nº 9.394 de 20 de dezembro de 1996. Disponível em:

http://www.planalto.gov.br/ccivil_03/leis/L9394.htm. Acesso em: 22 abr. 2017.

BRASIL. Lei $\mathbf{n}^{\circ} \mathbf{1 1 . 8 9 2}$, de 29 de dezembro de 2008. Institui a Rede Federal de Educação Profissional, Científica e Tecnológica, cria os Institutos Federais de Educação, Ciência e Tecnologia, e dá outras providências. Lei de Criação dos Institutos Federais de Educação, Ciência e Tecnologia. Disponível em: http://www.planalto.gov.br/ccivil_03/_ato2007-2010/2008/lei/l1 1892.htm. Acesso em: 10 dez. 2016.

BRASIL. Lei $n^{\circ} 13.415$ de 16 de fevereiro de 2017 (LEI ORDINÁRIA). Política de Fomento à Implementação de Escolas de Ensino Médio em Tempo Integral, 2017. Disponível em: http://www.planalto.gov.br/ccivil_03/_ato20152018/2017/lei/l13415.htm. Acesso em: 15 dez. 2017.

DORE, R. Afinal, o que significa o trabalho como princípio educativo em Gramsci? Cad. Cedes, Campinas, v. 34, n. 94, p. 297-316, set.- dez., 2014. Disponível em: http://www.scielo.br/pdf/ccedes/v34n94/0101-3262-ccedes34-94-0297.pdf. Acesso em: 19 maio 2019.

DRAGUNOVA, T. V. Características psicológicas del adolescente. In: PETROVSKI, A. Psicologia evolutiva y pedagógica. Moscou: Editorial Progresso, 1973, p. 120-175.

DUARTE, N. A individualidade para-si: contribuição a uma teoria históricocrítica da formação do indivíduo. 3. ed. rev. Campinas, SP: Autores Associados, 2013.

ELKONIN, D. Sobre el problema de la periodizacion del desarrollo psiquico en la infância. In: SHUARE, M. La psicologia evolutiva Y pedagogica en la URSS. Antología. Editorial Progreso: Moscú, 1987, p. 104-124. 
FOUCAULT, M. Vigiar e punir: nascimento da prisão. Tradução: Raquel Ramalhete. Petrópolis: Vozes, 1987.

HELLER, A. O cotidiano e a História. Tradução: Carlos Nelson Coutinho e Leandro Konder. 7 ed. São Paulo: Paz e Terra, 2004.

JESUS, A. T. de. O pensamento e a prática escolar de Gramsci. 2 ed. Campinas, SP: Autores Associados, 2005.

KOSIK, K. Dialética do concreto. Rio de Janeiro: Paz e Terra, 1976.

LEAL, Z. F. de R. G.; MASCAGNA, G. C. Adolescência: trabalho, educação e a formação omnilateral. In: MARTINS, L. M. et al. (org.). Periodização

Histórico-Cultural do desenvolvimento psíquico: do nascimento à velhice. Campinas, SP: Autores Associados, 2016, p. 221-237.

MARTINS, L. M. As aparências enganam: divergências entre o Materialismo Histórico Dialético e as abordagens qualitativas de pesquisa. Anais da 29a Reunião Anual da ANPEd, Educação, cultura e conhecimento na contemporaneidade: desafios e compromissos, Caxambu, 2006, p. 1-17.

MARTINS, L. M. O desenvolvimento do psiquismo e a Educação Escolar: contribuições à luz da psicologia histórico-cultural e da pedagogia históricocrítica. Campinas-SP: Autores Associados, 2013.

MOURA, D. H. Educação Básica e Educação Profissional e Tecnológica: dualidade histórica e perspectivas de integração. Holos, Ano 23, v. 2, 2007. Disponível em:

http://www2.ifrn.edu.br/ojs/index.php/HOLOS/article/viewFile/11/110. Acesso em: 15 fev. 2018.

MOURA, D. H.; LIMA FILHO, D. L.; SILVA, M. R. Politecnia e formação integrada: confrontos conceituais, projetos políticos e contradições históricas da educação brasileira. Revista Brasileira de Educação, v. 20, n. 63, out.-dez., 2015, p. 1057-1080. Disponível em:

http://www.redalyc.org/articulo.oa?id=275421 18013. Acesso: 01 jul. 2019.

PACHECO, E. Os Institutos Federais: uma revolução na Educação Profissional e Tecnológica. Natal: IFRN, 2010.

SAVIANI, D. O conceito dialético de mediação na pedagogia históricocrítica em intermediação com a psicologia histórico-cultural. Germinal: Marxismo e Educação em Debate, Salvador, v. 7, n. 1, p. 26-43, jun. 2015.

SILVA, C. J. R. (org.). Institutos Federais lei n 11.892, de 29/11/2008:

comentários e reflexões. Natal: IFRN, 2009. Disponível em: http://portal.mec.gov.br/index.php?option=com_docman\&view=download 
\&alias=3753-lei-1 1892-08-if-comentadafinal\&ltemid=30192. Acesso em: 15 jan. 2018.

SILVA, M. C. A. da; GASPARIN, J. L. A segunda Revolução Industrial e suas influências sobre a educação escolar brasileira. In: VII seminário de estudos e pesquisas, 2006, campinas - SP. HISTEDBR-VII seminário nacional de estudos e pesquisas "História, Sociedade e Educação no Brasil". Campinas - SP: UNICAMP, 2006. v. 1. p. 1-20. Disponível em: http://www.histedbr.fe.unicamp.br/acer_histedbr/seminario/seminario7/TRAB ALHOS/M/Marcia\%20CA\%20Silva\%20e\%20\%20Joao\%20L\%20Gasparin2.pdf. Acesso em: 10 jan. 2018.

SZYMANSKI, H. A entrevista reflexiva: um olhar psicológico sobre a entrevista em pesquisa. In: SZYMANSKI, H. (org.). A entrevista na pesquisa em educação: a prática reflexiva. 5 ed. Campinas, SP: Autores Associados, 2018, p. 9-60.

TULESKI, S. C.; EIDT, N. M. A periodização do desenvolvimento psíquico: atividade dominante e a formação das funções psíquicas superiores. In: MARTINS, L. M.; ABRANTES, A. A.; FACCl, M. G. D. (org.). Periodização histórico-cultural do desenvolvimento psíquico: do nascimento à velhice. Campinas, SP: Autores Associados, 2016, p. 35-61.

VYGOTSKI, L. S. El problema de la edad. In: VYGOTSKI, L. S. Obras Escogidas IV: Psicología infantil. Madrid: Visor, 1996, p. 251-273.

VIGOTSKI, L. S. A construção do pensamento e da linguagem. Trad. Paulo Bezerra. São Paulo: Martins Fontes, 2000.

Recebido em: 01 de novembro de 2019 Aprovado em: 12 de janeiro de 2020 